\title{
Colonoscopy quality: continuous improvement towards perfection
}

\section{(ㄷ)(1) $\Theta$}

\author{
Authors \\ Anna Rawa-Golebiewska ${ }^{1}$, Michal F. Kaminski ${ }^{1,2,3}$ \\ Institutions \\ 1 Department of Gastroenterological Oncology and \\ Department of Cancer Prevention, The Maria \\ Sklodowska-Curie Institute - Oncology Center, Warsaw, \\ Poland \\ 2 Department of Gastroenterology, Hepatology and \\ Oncology, Medical Center for Postgraduate Education, \\ Warsaw, Poland \\ 3 Institute of Health and Society, University of Oslo, Oslo, \\ Norway \\ Bibliography \\ DOI https://doi.org/10.1055/a-0732-5216 | \\ Endoscopy International Open 2018; 06: E1310-E1311 \\ (c) Georg Thieme Verlag KG Stuttgart · New York \\ ISSN 2364-3722 \\ Corresponding author \\ Anna Rawa-Golebiewska, MD, Department of \\ Gastroenterological Oncology, Institute of Oncology, \\ Roentgen Street 5, Warsaw, Poland \\ Fax: +48 225463057 \\ a_golebiewska@interia.pl
}

Kaizen is a Japanese philosophy of continuous improvement towards perfection mostly applied in business but also in healthcare. Screening colonoscopy is a perfect landscape for kaizen because flexible endoscopy technology is led by Japanese companies and high-quality examination is a key for colorectal cancer (CRC) screening effectiveness. One of the key quality measures for screening colonoscopy is adenoma detection rate (ADR), which is defined as a percentage of colonoscopies with at least one adenoma identified [1]. Suboptimal ADR is associated with an increased risk of interval CRC and CRC death [2, 3]. That is why both European and American guidelines currently recommend a minimum ADR of $25 \%$ for screening colonoscopy $[1,4]$.

In the current issue of the Endoscopy International Open, Leon Moreno J.F. presented a retrospective study analyzing ADR values in one of the few centers in Peru offering screening colonoscopy [5]. The report was based on 595 patients aged 50 years or more who underwent screening colonoscopy in a tertiary referral center between January 2016 and June 2017. The overall ADR values were $29.7 \%$ and individual ADR values for eight endoscopists participating in the study ranged between $25.0 \%$ and $34.4 \%$. This means that both overall and each endoscopist separately met the current minimum ADR standard of $25 \%$. This notable achievement was likely driven by a policy employed in the center to photo-document cecal intubation, keep colonoscope withdrawal time between 7 and 10 minutes, double or meticulously inspect right colonic folds and use dynamic position changes of patients. The author also emphasized lack of significant differences in ADR values between endoscopists involved in the study. Although the author is to be applauded for continuous small improvements that were already made, further refinements are needed to strive for perfection according to the kaizen philosophy.

Although an ADR of $25 \%$ is a minimum standard, the target standard is unknown and there is evidence for further reduction of interval CRC beyond $25 \%$ up to $34 \%$ [3]. There is also evidence that improving endoscopists' performance by reaching or maintaining the highest ADR quintile is associated with reduction in interval CRC and death [6]. Furthermore, in Leon Moreno's report, the number of colonoscopies that were used to calculate individual endoscopist ADRs were relatively low, partially explaining lack of significant differences between physicians. It has been shown that a large number of colonoscopies (e.g. 500) are needed to accurately measure [7]. Looking very conservatively at Leon Moreno's data, only one endoscopist for sure met the required benchmark ADR of $25 \%$ because the lower confidence interval of his ADR was beyond $25 \%$. Finally, the ADR values in Leon Moreno's study were not calculated according to the recommendations [1]. The author excluded colonoscopies with inadequate bowel preparation and incomplete which could have relatively boosted ADR in the study cohort.

Striving for perfection in screening colonoscopy performance, the author could have also focused on other than ADR key quality measures. Of the seven key quality measures of colonoscopy recommended by the European Society for Gastrointestinal Endoscopy guidelines [1], the author could have easily assessed at least three additional ones: rate of adequate bowel preparation (620 out of 649 patients, $95.5 \%$ ), cecal intubation 
rate (presented value is adjusted for bowel preparation which is inappropriate) and rate of appropriate polypectomy technique (the author collected the data without fully presenting them). To complete the picture of colonoscopy quality at the study center complication rate, patient experience and rate of appropriate post-polypectomy surveillance should have been measured as well [1].

In conclusion, the author set an example of how to start monitoring colonoscopy quality and how to implement several small improvements to achieve minimum standards of ADR both at individual and service level. Further efforts are needed to continue improvement towards effective, safe and comfortable colonoscopy.

\section{Competing interests}

None

\section{References}

[1] Kaminski MF, Thomas-Gibson S, Bugajski M et al. Performance measures for lower gastrointestinal endoscopy: a European Society of Gastrointestinal Endoscopy (ESGE) Quality Improvement Initiative. Endoscopy 2017; 49: 378-397

[2] Kaminski MF, Regula J, Kraszewska E et al. Quality indicators for colonoscopy and the risk of interval cancer. N Engl J Med 2010; 362: $1795-1803$

[3] Corley DA, Jensen CD, Marks AR et al. Adenoma detection rate and risk of colorectal cancer and death. N Engl J Med 2014; 370: 1298 1306

[4] Rex DK, Schoenfeld PS, Cohen J et al. Quality indicators for colonoscopy. Gastrointest Endosc 2015; 81: $31-53$

[5] León Moreno JF. ADR evaluation of screening colonoscopies during 2016-2017 in a private health clinic in Peru. Endosc Int Open 2018; 06: E1304-E1309

[6] Kaminski MF, Wieszczy P, Rupinski M et al. Increased rate of adenoma detection associates with reduced risk of colorectal cancer and death. Gastroenterology 2017; 153: $98-105$

[7] Do A, Weinberg J, Kakkar A et al. Reliability of adenoma detection rate is based on procedural volume. Gastrointest Endosc 2013; 77: 376 380 